\title{
O Turismo no Quarteirão Jorge Amado, Ilhéus (Bahia, Brasil): integrar é preciso
}

\author{
Tourism on the Jorge Amado Block, Ilhéus (Bahia, Brazil): integration is needed
}

\author{
Edivasco dos Reis Carneiro (CARNEIRO, E. dos R.); Renata Coppieters Oliveira de Carvalho \\ (CARVALHO, R. C. O. de); Idevaldo José dos Santos (SANTOS, I. J. dos S.); Mayne da Silva Santos \\ (SANTOS, M. da S.); Natanael Reis Bonfim (BONFIM, N. R.)
}

\begin{abstract}
RESUMO - O Quarteirão Jorge Amado (QJA), circuito turístico de Ilhéus (Bahia), apresenta-se como um importante atrativo turístico local. Assim, o artigo objetivou apreender a percepção dos atores sociais envolvidos com a atividade turística no QJA acerca da utilização dos atrativos presentes nesse espaço. Para tanto, foram realizadas entrevistas semi-estruturadas e os sujeitos foram escolhidos por amostragem não-probabilística intencional. A partir dos resultados obtidos, identificou-se que a falta de integração entre os diferentes atores desse espaço turístico correspondeu ao maior agravante para que as suas potencialidades não tivessem um total aproveitamento. Nesse sentido, propõe-se a criação de um calendário único para as atividades realizadas por esses atrativos. Visto o exposto, espera-se contribuir, de forma inicial, com a possibilidade de uma maior integração entre os atores envolvidos na atividade turística do local pesquisado; promovendo, por sua vez, a sustentabilidade socioambiental, cultural e turística do mesmo.
\end{abstract}

Palavras-chave: Turismo; Cultura; Planejamento; Quarteirão Jorge Amado; Ilhéus.

ABSTRACT - The Jorge Amado Block (Q JA), a Ilhéus (Bahia) tourist circuit, presents itself as an important local tourist attraction. Thus, the article aimed to understand the perception of the social actors involved with tourism activity in QJA about the use of the attractions in that space. In this way, it was accomplished with semi-structured interviews and the subjects were chosen for intentional nonprobabilistic sampling. From the results obtained, it was identified that the lack of integration among the different actors in this area corresponded to the greater aggravating for that its potential has not had a full utilization. In this sense, it is proposed to create a single calendar for activities undertaken by these attractions. Given the foregoing, it is expected to contribute, of an initial form, with the possibility of a better integration among the involved actors in the tourism; promoting, this way, the cultural, social and environmental sustainability and tourism in that place.

Key words: Tourism; Culture; Planning; Jorge Amado Block; Ilhéus.

\footnotetext{
* Edivasco dos Reis Carneiro - Graduação em Geografia pela Universidade Estadual de Feira de Santana (UEFS). Mestrado em Cultura e Turismo pela Universidade Estadual Santa Cruz (UESC, Ilhéus, Bahia). Bolsista da Fundação de Amparo à Pesquisa do Estado da Bahia (FAPESB). Endereço: Rua Eustáquio Bastos, nº 157 (Pontal). CEP: 456654-120 - Ilhéus - Bahia (Brasil). Telefone: (75) 9988-6230. E-mail: edircarneiro@ hotmail.com.

Renata Coppieters Oliveira de Carvalho - Graduação em Turismo e Hotelaria pela Universidade do Estado da Bahia (UNEB). Especialização em Interpretação do Patrimônio com Comunidades pela Faculdade de Turismo da Bahia (FACTUR). Mestranda em Cultura e Turismo (UESC). Professora do Curso de Turismo da UNEB Campus XVIII - Eunápolis (Bahia). Endereço: Cond. Bosque Imperial, bloco 10, ap. 504 (São Rafael). CEP: 40000-000 - Salvador - Bahia (Brasil). Telefone: (71) 3213-6768. E-mail: renatacopi@ hotmail.com.

Idevaldo José dos Santos - Graduação em Comunicação Social Rádio e TV (UESC). Especialização em Economia de Empresas (UESC). Mestrando em Cultura e Turismo (UESC). Endereço: Rua Dr. Manoel Lins, nº 162 (Centro). CEP: $45615-970$ Buerarema - Bahia (Brasil). Telefone: (73) 8834-4266. E-mail: idevaldojose @ hotmail.com.

Mayne da Silva Santos - Graduação em Turismo pela Faculdade de Tecnologia e Ciências. Especialização em Gestão e Educação Ambiental pela Faculdade Santo Agostinho. Mestranda em Cultura e Turismo (UESC). Endereço: Rua Manoel F. de Almeida, $n^{\circ}$. 253 (Anfrísio Xavier Góes). CEP: 45680-970 - Uruçuca - Bahia (Brasil). Telefone: (73) 8124-2281. E-mail: maynesantos@yahoo.com.br.

Natanael Reis Bomfim - Graduação em Geografia pela Universidade Católica do Salvador. Mestrado em Educação pela Universidade Federal da Bahia. Doutorado em Educação pela Universidade de Montreal (Canadá). Professor das disciplinas: Planejamento Sustentável do Turismo no Mestrado de Cultura e Turismo e Cartografia Temática na Licenciatura e Bacharelado em Geografia (UESC). Endereço: Rodovia Ilhéus/Itabuna, Km 16. CEP: 45650-000 - Ilhéus - Bahia (Brasil). Telefone: (73) 3680-5141. E-mail: nabom@hotmail.com.
} 


\section{INTRODUÇÃO}

A cidade de Ilhéus dista $465 \mathrm{~km}$ de Salvador, capital do estado da Bahia (FIGURA 1). Esse município ficou conhecido internacionalmente como um dos maiores produtores de cacau, chegando, em 1920, a ostentar o primeiro lugar, sendo responsável por cerca de $85 \%$ da produção de cacau mundial (IBGE, 2010). Após a consolidação da lavoura de cacau, a sociedade local passou a ter o seu ritmo ditado pelas necessidades do mercado externo. Contudo, principalmente pelo surgimento da praga, popularmente conhecida como "vassoura de bruxa", devastou-se parte da produção de cacau; dessa forma, outras atividades econômicas tiveram que ser inseridas para a saída da pior crise da história local (LEAL, 2005).

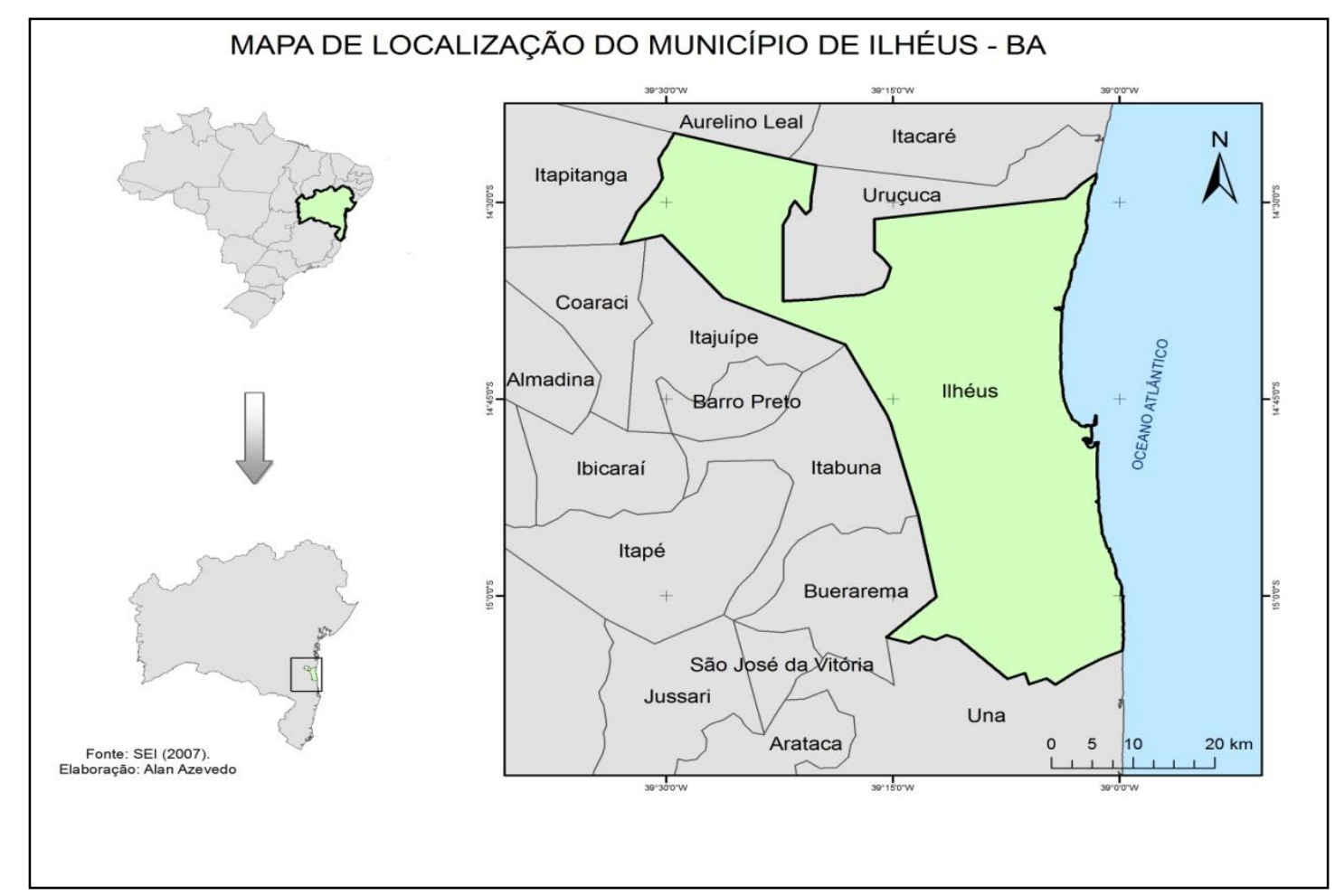

FIGURA 1 - LOCALIZAÇÃO DO MUNICÍPIO DE ILHÉUS, BAHIA (BRASIL). FONTE: ELABORAÇÃO DE LILIANE GÓES (2010), DISPONÍVEL EM ARGOLO (2010).

Na busca de outros caminhos para o seu desenvolvimento, a região aposta e se respalda na diversidade econômica. Dentre vários setores, uma possibilidade é o turismo, pois diante das riquezas naturais e patrimônio histórico-cultural preservados, a cidade se consagra pela "rica" memória historiográfica e, principalmente, pela 
"paradisíaca" imagem construída pela literatura, e pelo cinema (VIEIRA JÚNIOR; ANDRADE, 2007). Assim, o município de Ilhéus passou a integrar a Zona Turística da Costa do Cacau, localizada na Região Sul da Bahia (FIGURA 2).

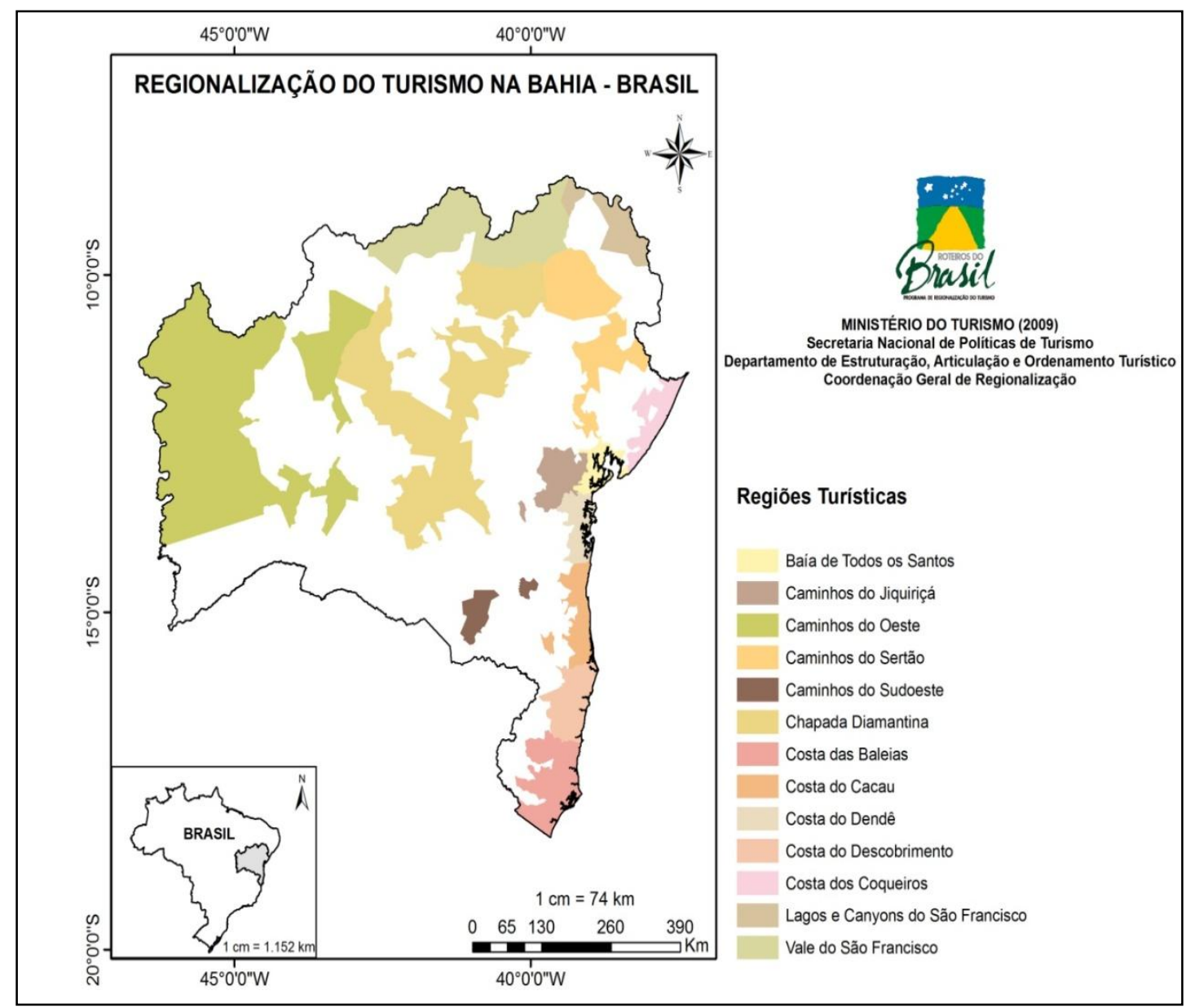

FIGURA 2 - MAPA DA REGIONALIZAÇÃO DO TURISMO NO ESTADO DA BAHIA. FONTE: ELABORAÇÃO DE LILIANE GÓES (2010), DISPONÍVEL EM ARGOLO (2010).

Com aquele cenário, o munícipio com 221.883 habitantes em uma área aproximada de $1.841 \mathrm{~km}^{2}$ (IBGE, 2010) apresenta-se como um dos mais antigos e mais conhecidos em nível nacional, evidenciado pelas suas potencialidades naturais e culturais. A cidade de Ilhéus é um dos destinos turísticos mais procurados do Nordeste brasileiro, principalmente por ter sido palco das histórias de um dos mais populares escritores do país, Jorge Amado, que em seus romances divulgou internacionalmente a cidade (BAHIA, 2002). Dessa forma, na década de 90 do século XX, a Secretaria de Turismo e a Fundação Cultural de Ilhéus criaram o Projeto do Quarteirão Jorge Amado 
(QJA) que incluiu a proposição de divisão da cidade em dois circuitos: O Cravo e o Canela.

O Circuito Cravo é composto pela Catedral de São Sebastião, Bar Vesúvio (em destaque na FIGURA 3), Teatro Municipal, Casa de Cultura Jorge Amado, Associação Comercial de Ilhéus, Estátua de Sapho, Palácio Paranaguá, Igreja Museu São Jorge, Casa do Coronel Misael Tavares, Casa de Tonico Bastos; e o Circuito Canela, é composto pelo Ilhéos Hotel e Restaurante do Coronel, antigo Porto de Ilhéus, Bataclan, Restaurante Velhos Marinheiros, Cristo Redentor e Outeiro de São Sebastião (MENEZES, 2003).

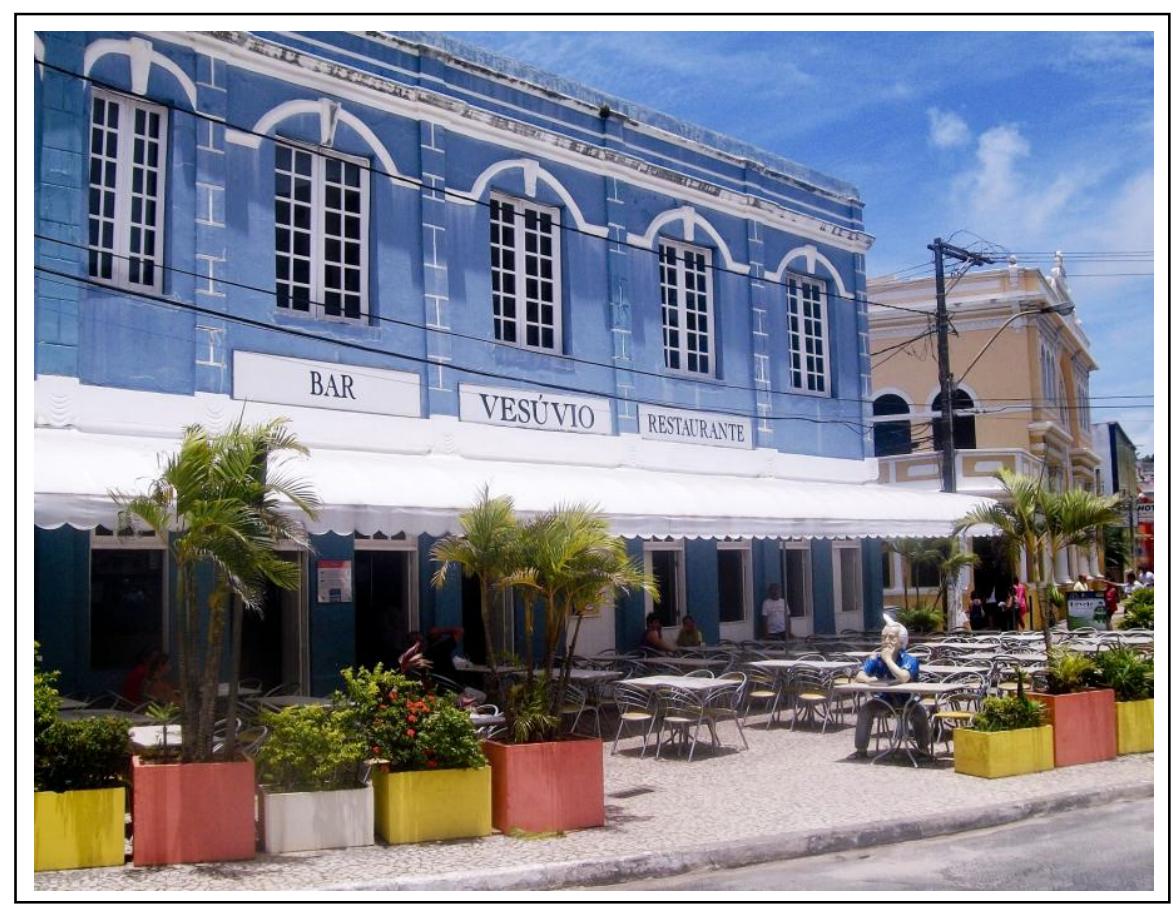

\section{FIGURA 3 - BAR VESÚVIO.}

FONTE: CARNEIRO, 2010.

A construção acima ficou famosa após ser imortalizada na obra Gabriela, Cravo e Canela ${ }^{1}$ do escritor Jorge Amado. No mesmo ambiente, é possível notar, também, a estátua do escritor sentado à mesa. $\mathrm{O}$ bar constitui-se em um marco com grande função turística, estando localizado na parte central do Quarteirão.

\footnotetext{
${ }^{1}$ Romance escrito no ano de 1958, do baiano Jorge Amado, que influenciou e continua influenciando a história local.
} 
Segundo Vinhaes (2001), em sete de abril de 1969, o então prefeito e presidente da Câmara Municipal, João Alfredo Amorim de Almeida realizou várias obras de infraestrutura, entre elas a pavimentação da Avenida 2 de Julho, para fins de utilização turística. Em 1971, o prefeito seguinte Edmond Darwich, deu continuidade às obras da avenida até o Bar Vesúvio com a mesma finalidade.

Ainda, segundo o referido autor, no ano de 1984, foi criada a comissão prómemória, integrada por Fábio Goulart, Secretário de Educação; Henrique Almeida, Chefe da Divisão de Turismo; e por Arléo Barbosa (Historiador) e Horizontina Gray (Educadora). Essa comissão conseguiu promover a reurbanização da Avenida 2 de Julho, a qual faz parte do Centro Histórico de Ilhéus.

Entendendo a importância cultural, histórica e turística desses patrimônios, esse estudo objetivou apreender a percepção dos atores sociais envolvidos com a atividade turística no Quarteirão Jorge Amado (QJA) acerca da utilização dos atrativos turísticos presentes nesse espaço a fim de sugerir estratégias de ações integradoras para uma efetiva utilização dos seus atrativos turísticos a partir de três pilares fundamentais: comunicação, educação e planejamento.

Nesse sentido, considera-se que através de ações de integração é que poder-se-á promover o fortalecimento das instituições locais que o compõem, em especial os citados como atrativos do Quarteirão. Assim, acredita-se que possa haver um melhor aproveitamento do espaço proposto, promovendo, por conseguinte, a sustentabilidade socioambiental, cultural e turística do mesmo.

\section{REVISÃO DE LITERATURA}

Aqui se buscou avaliar os resultados da pesquisa acerca do espaço urbano, do planejamento turístico e da atividade turística no Quarteirão Jorge Amado, como forma de apreender pistas que remetessem à elaboração de estratégias que pudessem servir para um planejamento integrado do Quarteirão. 
Segundo Santos (1988) apud Carlos (1994)², o espaço urbano é o local onde as relações sociais irão se materializar, ou seja, é o conteúdo, enquanto que a cidade é a forma, o contexto físico. Porém, não se pode fazer uma separação entre esses dois elementos, pois o espaço urbano passa a ser o local de produção, em que as trocas sociais e naturais terão uma dinâmica própria e contínua ao longo do tempo, evidenciando formas de consumir, pensar e sentir em um lugar. Compreende-se ainda, segundo Siviero, que o espaço urbano é:

[...] condicionante social, ou seja, o lugar onde as diversas classes sociais vivem e se reproduzem. Envolve também as crenças, valores e mitos criados na sociedade e projetados nas formas espaciais: monumentos, lugares sagrados, dentre outros. Além de ser cenário e objeto das lutas sociais, que buscam, entre outros, o direito à cidade e à cidadania plena e igual para todos (SIVIERO, 2006, p. 54).

Observa-se, assim, que o sentido de lugar e de seus objetos é valorizado, ou não, pela sociedade que ali vive e esse sentido de valor ainda se modificará ao longo do tempo, pois as pessoas que ali circulam não serão as mesmas.

Esse espaço fica ainda mais complexo quando a atividade turística, através das relações que se estabelecem entre os turistas e os visitados, imprimem elementos marcantes no lugar turístico, evocando as trocas simbólicas e (re) significando suas funções (MARTINS, 2003). Faz parte da atividade turística, despertar o interesse do turista para que este se desloque a fim de conhecer a peculiaridade de um local, mesmo que as funções do espaço sejam transformadas apenas para atender a este público em especial. Assim, o espaço turístico passa a ser o espaço urbano com novos agentes externos participando de forma efetiva, ou não, na (re) construção desse lugar. Nesse artigo, estipulou-se como definição para experiência turística a seguinte:

[...] uma vivência pessoal que interfere no cotidiano do sujeito, reflexo de aspectos tangíveis e intangíveis que, em diferentes graus, impactam e sofrem impactos de acontecimentos únicos e memoráveis gerando emoções, encantamento, histórias, sonhos e vivências que são utilizados para, entreter, fascinar e cativar o turista, resultando em conhecimentos e valores (GÂNDARA, 2009).

\footnotetext{
${ }^{2}$ SANTOS, M. A urbanização brasileira. 1. ed., São Paulo: HUCITEC, 1998.
} 
Observa-se que a atividade turística deve promover o bem estar das comunidades locais para que um espaço seja sustentável, pois:

Deve-se ser filosofia básica de qualquer planejamento, desenvolvimento e gestão da atividade turística (destino/produto/empresa), o conceito de desenvolvimento sustentável, considerando este como um instrumento/ modelo de desenvolvimento que relaciona os aspectos socioculturais, ambientais, econômicos e de participação da comunidade local, buscando tanto a satisfação de visitantes e visitados como a conservação do meio ambiente como forma de permitir a continuidade de sua utilização a longo prazo (GÂNDARA, 2001, p. 35).

Desse modo, pode-se observar que o turismo tem um caráter íntimo com a cultura, com a formação e transformação da identidade, bem como com a manutenção e preservação dos patrimônios históricos, naturais e culturais de determinada localidade (BRASIL, 2008). Assim, o turismo tem a possibilidade de despertar e trazer a tona soluções para antigos problemas: marginalidade, perda de autonomia, exclusão e novos desafios, tais como: sustentabilidade, recursos econômicos e intercâmbio cultural (BARRETTO, 2000).

A participação dos diferentes atores sociais no processo de planejamento da atividade turística tem sido apontada como uma necessidade por diversos pesquisadores. Bomfim (2008) afirma que o estudo sobre a percepção do espaço turístico urbano pela comunidade, merece atenção especial tendo em vista que as perspectivas de inspiração interdisciplinar consideram que as significações e práticas que os atores sociais atribuem ao seu espaço de vivência funcionam como uma forma de reconstrução de sua realidade socioespacial. Acredita-se que estas significações permitem a compreensão dentro de qual mundo e como eles vivem, e de afirmar que as suas percepções são pertinentes para melhor compreender-se o fenômeno turístico e apresentar estratégias que permitam a sua sustentabilidade em diversas dimensões, a saber: cultural, social, ambiental e econômica.

Irving (2002); Brandon (2005); Kummer (2008) corroboram com essas idéias quando afirmam que os financiadores de projetos que visam o desenvolvimento das localidades, consideram essa participação como mecanismo ideal para o alcance do desenvolvimento adequado dessa atividade. Isso se dá, por esta ser vista como uma possibilidade de que os anseios de diferentes atores sociais sejam ouvidos, atendidos e 
com isso os resultados de planejamento para o desenvolvimento das comunidades sejam maximizados.

Apesar disso, esse tipo de participação ainda não é utilizado por todas as gestões públicas. Muito menos é compreendido como elemento fundamental para a gestão eficaz dos destinos turísticos. No entanto, isso possivelmente não se dá somente pela falta de entendimento da importância da participação, mas também, pelo fato de que gerir de forma compartilhada é possibilitar que outros agentes sociais também detenham ou participem dos espaços de poder e decisão.

Nesse sentido, a participação referida significa um processo de construção coletiva, no qual, todos participam de forma igualitária e ativa, trabalhando para alcançarem um objetivo comum. Para tanto, o nível de participação citado aqui é o mais alto, o da autogestão, o qual, segundo Bandeira (1999), refere-se ao nível mais elevado dos esforços participativos, em que as partes interessadas interagem em processos de aprendizado que otimizam o bem-estar de todos os envolvidos.

Ainda para esse autor, a participação social é defendida especialmente por possibilitar o aumento da eficácia das ações governamentais. E que, a falta de participação da comunidade é apontada pelas principais instituições internacionais da área de fomento do desenvolvimento, como uma das causas do fracasso de políticas, programas e projetos de diferentes tipos. E ele afirma que:

[...] como consequência dessa falta de envolvimento da comunidade, muitos programas e projetos governamentais concebidos e implantados de cima para baixo não sobrevivem às administrações responsáveis pelo seu lançamento. Acabam por ser substituídos por outros igualmente efêmeros, num ciclo patético que envolve grande desperdício de recursos e só contribui para aumentar o descrédito em relação à eficácia das ações do setor público (BANDEIRA, 1999, p. 12).

Segundo Tosun (2000) apud Beni $(2006)^{3}$, as principais limitações para a participação da comunidade no processo de planejamento do turismo são operacionais, estruturais e culturais. Mais ainda, a participação da comunidade requer tempo, dinheiro e habilidade para ser organizada, não se limitando à problemática e dificuldade de entender o processo participativo.

${ }^{3}$ TOSUN, C. Limits to community participation in the tourism development process in developing countries. In: Tourism management, v. 21, p. 613-633, 2000. 
Segundo Leme et al. (2008), em pesquisa prévia sobre "A percepção dos trabalhadores do Quarteirão Jorge Amado, Ilhéus - Bahia, em relação ao patrimônio arquitetônico local" foi identificado que os trabalhadores, em sua maioria, não conheciam a história e representação desse patrimônio, entendendo-se a necessidade da estruturação de novas análises para o desenvolvimento sustentável através da percepção da comunidade local e da capacidade de carga dos equipamentos situados nesse Quarteirão.

\section{MÉTODOS E TÉCNICAS DE INVESTIGAÇÃO}

Este estudo insere-se numa linha de pesquisa centrada no conteúdo com uma metodologia de tradição hermenêutico/interpretativa (SAVOIE-ZAJC; KARSENT, 2000). Para o entendimento de como os atores sociais envolvidos nas atividades do QJA percebem esse lugar turístico, buscou-se selecionar instrumentos, tipo de amostragem e análise de interpretação dos dados que fossem coerentes com a questão e objetivos de pesquisa.

\subsection{INSTRUMENTOS E AMOSTRAGEM}

Para o entendimento de como funcionava o QJA, foram aplicadas entrevistas semi-estruturadas não dirigidas (MARCONI; LAKATOS, 2004) a alguns dos responsáveis pelos equipamentos que faziam parte da lista de atrativos turísticos do QJA citada. A escolha dos participantes e dos equipamentos dessa pesquisa se deu por amostragem não-probabilística intencional (LAKATOS; MARCONI, 2002).

Como critérios básicos para seleção dos participantes adotaram-se, aleatoriamente, aqueles sujeitos que lidavam diretamente com os equipamentos associados aos atrativos turísticos no QJA, perfazendo um total de dez entrevistas. Para os equipamentos turísticos buscou-se aliar as características de proximidade entre os atrativos, maior evidência com os romances de Jorge Amado e novos pontos culturais vivenciados pela comunidade. 


\subsection{TIPO DE PESQUISA, DE ANÁLISE E INTERPRETAÇÃO DOS DADOS}

A pesquisa empírica foi realizada no dia dezessete de agosto de 2009 das oito horas da manhã às dezessete horas da tarde. E, também, no dia dezenove, das quatorze às dezoito horas da tarde de 2009. Em complemento, utilizou-se da pesquisa documental e bibliográfica para fundamentar a proposta do presente artigo.

Os dados foram tabulados e analisados pela técnica de análise do conteúdo de Bardin (2002) e os resultados da pesquisa foram comparados com as proposições do projeto de revitalização do QJA, promovido pela Prefeitura Municipal de Ilhéus em governos pretéritos.

Com isso, espera-se contribuir para um melhor desenvolvimento da atividade turística do município de Ilhéus, promovendo, através da educação dos seus diferentes atores, não apenas o conhecimento do legado artístico-cultural de Jorge Amado, mas, sobretudo, auferir benefícios econômicos e sociais para a comunidade local, além da preservação do conjunto arquitetônico que compõe o QJA e do fortalecimento dos seus aspectos identitários.

\section{RESULTADOS E DISCUSSÃO}

A partir do estudo realizado no QJA, identificou-se que a falta de integração entre os diferentes atores desse espaço turístico correspondeu ao maior agravante para que as suas potencialidades não tivessem um total aproveitamento.

Segundo os dados coletados, nenhuma das instituições havia conseguido até aquele momento desenvolver parcerias que viabilizassem uma melhor utilização e/ou desenvolvimento desse espaço. Constatou-se, ainda, a partir de outros estudos já realizados, que a comunidade e o trade turístico não conheciam os equipamentos turísticos e históricos do QJA (LEME et al., 2008).

Como fator agravante desses entraves, verificou-se que os agentes dos diferentes equipamentos turísticos estavam produzindo suas ações, eventos e atividades de forma individualizada. Também, que a gestão pública ainda não havia desenvolvido um espaço para que acontecesse o planejamento compartilhado do QJA. Que não existia um 
calendário único ou algum tipo de informe que agrupasse e apresentasse as atividades que aconteciam nos equipamentos desse espaço urbano, cultural e histórico; existindo tão somente uma promoção individual de cada equipamento.

Um processo participativo exige dos gestores a compreensão de que esse tipo de gestão demanda mais tempo de planejamento. Para Dias (2003), o planejamento nada mais é do que um processo dinâmico e permanente que incorpore, no máximo possível, a complexa realidade que pretende organizar. Desse modo, é necessário ouvir os diferentes atores sociais requerendo, também, investimento de capital e vontade para o acontecimento da mobilização e envolvimento desses agentes. Exige ainda que a gestão pública compreenda que a sua participação refere-se principalmente a coordenar os espaços de gestão e planejamento, no entanto os diferentes saberes apresentados, os divergentes níveis de conhecimento e atuação dos envolvidos passam a ter o mesmo valor que os seus, ou seja, uma construção coletiva. Segundo Chevitarese e Mattos (2006, p. 71),

\begin{abstract}
O nascer compartilhado se relaciona ao saber compartilhado e não a uma relação desigual de dominantes e dominados na qual o saber tem conotação direta com a concentração de poder e a exclusão social. A participação emerge neste cenário como um elemento de contracultura, mas provavelmente é a única garantia ética de sustentabilidade de um projeto efetivo de desenvolvimento.
\end{abstract}

Diante das potencialidades apresentadas pelo QJA, sabe-se que corresponde a um espaço de gestão compartilhada, no qual todos os atores envolvidos possam apresentar suas potencialidades e fragilidades, compreender as dos seus pares permitiria que novas atividades, ações e estratégias fossem definidas para aperfeiçoar o projeto proposto pelo poder público de revitalização e melhoramento do Quarteirão.

O valor da iniciativa da política pública do governo municipal, com o "Projeto Básico e Executivo de Requalificação Urbana do Centro Histórico de Ilhéus” possui os seus méritos, mas verificou-se, que somente o melhoramento físico não tornaria aquele espaço vivo, dinâmico e sustentável. Para tanto, seria preciso levar-se em conta que os atores sociais e a comunidade local pudessem se apropriar da sua história, cultura e participar das decisões e gestão local.

Dessa forma, passou-se a acreditar na criação de um espaço no qual a gestão do QJA pudesse ser construída pelos diferentes fatores envolvidos; no qual, iniciar-se-ia 
uma nova forma de engajamento e concepção de gestão política, estimulando e apresentando o olhar comunitário por um espaço que era de todos. A partir daí, haveria um melhoramento desse espaço, que é também turístico, no qual possivelmente se ofereceria melhores experiências que evidenciariam e apresentariam uma Ilhéus do ontem, uma Ilhéus de Jorge Amado e uma Ilhéus atual.

Direcionando-se a Ilhéus, pode-se destacar que os empresários apontaram os gestores como únicos responsáveis pela gestão do turismo, da cultura e do desenvolvimento local. Porém, esse espaço coletivo poderia oferecer uma nova perspectiva para os diferentes atores sociais do QJA. De acordo com Brandon (2005, p. 233),

[...] dar às pessoas mais oportunidades de participar efetivamente nas atividades de desenvolvimento [...] significa proporcionar condições para que elas mobilizem seu próprio potencial, sejam agentes sociais em vez de sujeitos passivos, gerenciem os recursos, tomem decisões e controlem as atividades que afetam suas vidas [...].

Portanto, é relevante que a gestão pública inicie esse processo, como forma de auxiliar que os diferentes atores sociais da comunidade, do trade turístico, dos movimentos sociais e culturais se envolvam e se sintam responsáveis pelo alcance do desenvolvimento sustentável local.

A participação no planejamento do QJA poderia contribuir para o desenvolvimento sustentável através da incorporação na tomada de decisão dos interesses das comunidades que seriam potencialmente afetadas (DRAKE, 1991 apud ARAÚJO, 2006) ${ }^{4}$; pois nesse caso seriam os empresários, os artistas, os gestores e a comunidade que vivenciam e fazem parte do espaço QJA, da história e da cultura ali produzida.

Para tanto, em turismo, o desenvolvimento sustentável deve ser entendido de:

[...] modo mais específico [...] se faz necessária a reintrodução de restrições de ordem ambiental ao processo de acumulação de capital e aos padrões de consumo que lhes são correspondentes. A aceitação dessas restrições por parte da população pressupõe um forte componente altruísta de solidariedade intra e intergerações (ROMEIRO, 2003, p. 26).

\footnotetext{
${ }^{4}$ DRAKE, S. P. Local participation in ecotourism projects. In: WHELAN, T. (ed.) Nature tourism: managing for the environment. Washington, D. C.: Island Press, p. 132-163, 1991.
} 
Desse modo, para a sustentabilidade do turismo, aponta-se a exigência da adoção de instrumentos de mensuração, como indicadores de desempenho e monitoramento, além do estabelecimento de limites às atividades do turismo. Desse modo, pode-se relatar que o turismo sustentável tem como "motivação o aprendizado, a contemplação e a conservação. É especializado com baixa capacidade de carga, discreto, educacional, conservacionista e produz retornos em benefícios tangíveis para comunidade local" (PETROCCHI, 2009).

Como um dos cernes da questão é a educação, entende-se conceitualmente segundo a Lei de Diretrizes e Bases da Educação Nacional, em seu Artigo $1^{\text {o }}$, que se assegura que "a educação abrange os processos formativos que se desenvolvem na vida familiar, na convivência humana, no trabalho, nas instituições de ensino e pesquisa, nos movimentos sociais e organizações da sociedade civil e nas manifestações culturais" (BRASIL, 1996, p. 1).

Contudo, o espaço público constrói um lugar comum entre os homens, sendo pensado não só como aquilo que é comum, e sim, como o que é comunicável se diferenciando das experiências estritamente subjetivas e pessoais. O desafio da comunicação, nesse caso, é mobilizar, tocar a emoção entre os atores envolvidos, sem também, manipulá-los, caso não ocorra assim, será artificial, autoritário e imposto. Para Cicília Peruzzo (1998), os movimentos sociais implicam o exercício da decisão compartilhada e requerem a existência de canais desobstruídos, informações abundantes, autonomia, co-responsabilidade e representabilidade.

Com isso, pode-se afirmar que a participação é um importante mecanismo impulsionador para os atores sociais, para que os mesmos se mobilizem e tomem uma decisão de engajamento em algum movimento. Vale ressaltar, que não é preciso que estas pessoas tenham carências e problemas em comum, mas que compartilhem valores e visões semelhantes, como acontece com os atores envolvidos no Quarteirão Jorge Amado.

\subsection{USO CULTURAL E TURÍSTICO NO ESPAÇO DO QJA}

A cidade de Ilhéus, e mais especificamente o QJA, apresenta uma riqueza histórica e cultural bastante singular da lavoura cacaueira no Brasil, demonstrando em 
seus atrativos um grande potencial para o desenvolvimento do turismo cultural. Dessa forma, a cultura na contemporaneidade, pode ser considerada como um importante vetor de fomento da atividade turística (CARNEIRO; MIDLEJ; PEREIRA, 2009).

Valorizar a cultura local, através de atividades culturais de forma integrada, auxilia no desenvolvimento do turismo, satisfazendo tanto aos turistas quanto a comunidade local e o trade turístico.

Alguns patrimônios histórico-culturais do QJA foram restaurados e/ou reformados através do Projeto Básico e Executivo de requalificação urbana do centro histórico de Ilhéus aprovado em 25 de Abril de $2007^{5}$ para atender as expectativas da atividade turística da região atrelada ao forte apelo de desenvolvimento econômico. Porém, restaurar ou melhorar a estrutura física do espaço turístico não garante a sua sustentabilidade. A memória é dinâmica nesse processo de lembrar e esquecer o tempo áureo do cacau através da visualização dos seus monumentos imponentes. Haverá, também, neste espaço turístico uma memória viva sendo percebida nas relações cotidianas de suas ruas e da sua comunidade que irá preservar, ou não, aquilo que lhe parece importante no momento.

Entretanto, verificou-se que os atrativos do QJA promoviam atividades culturais de forma desarticulada. Não havendo um calendário de atividades e nem meio de comunicação que pudesse informar ao turista ou morador as atividades que estivessem acontecendo durante a semana, ou mês do ano vigente. As atividades eram realizadas isoladamente com pouca divulgação, sendo esta uma reclamação constante das agências de viagens que não conseguiam vender os atrativos.

Essa realidade demonstrou, mais uma vez, que não havia um diálogo frequente entre os gestores dos atrativos pertencentes ao QJA, fazendo com que os proprietários dos mesmos fossem prejudicados.

A literatura brasileira no final do século XIX contribuiu para a valorização do passado, a fim de guardar como marco da herança cultural e identidade regional, tornando bastante propícia a interferência da atividade turística no momento em que estimula vontade de reprodução de condições cenográficas que remetessem a eventos romanceados (MENESES, 2004). Para esta afirmação, tem-se o exemplo dos romances

\footnotetext{
${ }^{5}$ Entrevista concedida por um representante da Prefeitura Municipal de Ilhéus no ano de 2009.
} 
de Jorge Amado que até os dias atuais são reconhecidos como os grandes estimuladores para o deslocamento de turistas a Ilhéus e as vivências no QJA.

Os espaços urbanos que eram utilizados na época do cacau são retratados em mistos de ficção e realidade nas obras de Jorge Amado, dando suporte ao espaço turístico existente. Segundo Boullón:

[...] o espaço turístico é consequência da presença e distribuição territorial dos atrativos turísticos, que não devemos esquecer, são a matéria-prima do turismo. Este elemento de patrimônio turístico, mais o empreendimento e a infra-estrutura turísticas são suficientes para definir o espaço turístico (BOULLÓN, 2002, p. 65).

Os locais de encontro e de vivência dos coronéis $^{6}$ são atrativos turísticos que contam em suas histórias e sua própria arquitetura, o passado que será experenciado pelo turista. Porém, percebeu-se que os equipamentos turísticos do QJA não tinham articulação integrada, limitando a vivência satisfatória do turista e cada vez mais a exclusão da comunidade local.

Assim, deve-se buscar a Interpretação do Patrimônio de forma a cumprir duas funções básicas: valorizar a experiência do visitante, levando-o a compreensão e apreensão do local visitado e a valorização do patrimônio, incorporando-o como atração turística (MURTA, 2002).

A interpretação do patrimônio não tem uma fórmula pronta, pois é necessário avaliar a comunidade, as suas interferências; é necessário conhecer as técnicas, aplicálas e sempre replanejar. Os interpretadores buscam compreender e valorizar com a comunidade a sua história, para que estes laços se fortaleçam e atraiam visitantes que compartilhem os seus significados e não se apropriem indevidamente de seus símbolos e produtos identitários.

\section{CONSIDERAÇÕES FINAIS}

É importante salientar que, os dados de pesquisa coletados em 2009 foram validados em 2010 através de reuniões envolvendo a participação dos atores sociais dos

\footnotetext{
${ }^{6}$ Termo utilizado para nomear os grandes produtores de cacau da região.
} 
diversos segmentos que atuam no Quarteirão Jorge Amado (Gestores da Prefeitura Municipal de Ilhéus, Empresários, Colaboradores de Empresas, entre outros). Essas novas informações foram comparadas com as informações anteriores e permitiram apresentar dados atualizados.

A partir das informações obtidas, referentes aos equipamentos turísticos do QJA, teve-se a constatação de não haver uma política clara de integração entre eles. Com isso, propôs-se a criação de um calendário único para as atividades realizadas pelo circuito turístico.

A criação desse calendário único poderia vir a possibilitar, também, o estímulo artístico-cultural da própria comunidade local através da realização de oficinas, apresentações de estratégias, levantamentos de potencialidades e fragilidades no intento de integrar às histórias e memórias vividas no passado com a produção cultural contemporânea. Por conseguinte, ao visitar esse espaço a comunidade e o turista/visitante poderiam acompanhar a evolução histórica das obras de Jorge Amado e suas interfaces com a arte contemporânea.

Para que o uso cultural e turístico do QJA fosse maximizado, propôs-se também a realização de novas atividades que atendessem a seis eixos temáticos:

1) Literatura - Sarau literário: realizando-se em praça pública em um dia específico da semana com período de duração de duas horas com artistas locais. A criança e Jorge: ocorrendo na Casa de Jorge Amado em períodos pré-determinados no calendário, tendo como público-alvo, crianças de escolas públicas do município e região;

2) Dança - realização de espetáculos de dança relacionados à obra de Jorge Amado, ou não, na Casa dos Artistas, no Teatro Municipal e em praça pública durante um dia específico da semana, com grupos locais e de outros municípios da região e do país;

3) Gastronomia - execução de Festivais, eventos e cursos sobre a comida eternizada na obra Amadiana e, também, relacionados à comida baiana. Estes eventos devendo ser realizados de acordo com o calendário proposto;

4) Cinema - efetivação de mostras com documentários sobre a região para a população local e para os turistas em dias específicos fixados pelo calendário do QJA; promoção de novas produções com o auxílio da Casa dos Artistas; por fim, a 
realização de um festival chamado: "5 minutos de cinema” no Teatro Municipal em data pré-estabelecida em calendário;

5) Teatro - execução de peças de Teatro de rua em um dia específico da semana durante a alta estação do período de dezembro a fevereiro; realização de peças de teatro todos os domingos no Teatro Municipal, estimulando a visitação ao QJA aos finais de semana;

6) Música - realização de Festivais de música no Teatro Municipal e na Casa dos Artistas com artistas locais; de workshops com artistas de renome nacional e internacional no Teatro Municipal ou na Casa dos Artistas; estímulo a apresentações de artistas locais nos equipamentos turísticos do QJA, como o Teatro Municipal e a Casa dos Artistas, através da realização de shows promocionais nesses espaços.

Através dessa proposta, acreditou-se e acredita-se que a utilização dos elementos culturais existentes na cidade de Ilhéus e, principalmente, no QJA poderia ser feita de forma mais satisfatória para todos os envolvidos com a atividade turística e que, por conseguinte, haveria a valorização do patrimônio cultural existente no Quarteirão.

Vale salientar, também, que é preciso estimular a interpretação do patrimônio neste espaço turístico para que haja a valorização da experiência do visitante no local. Por conseguinte, ocorreria uma maior compreensão dos visitantes em relação a esses atrativos e da própria comunidade local.

Visto o exposto, espera-se contribuir, de forma inicial, com a possibilidade de uma maior integração entre os atores envolvidos na atividade turística do local pesquisado; estimulando a criação e/ou fortalecimento dos movimentos culturais relacionados aos eixos propostos: Literatura; Dança; Música e artes em geral; Culinária; Teatro e Cinema. Isso só sendo possível a partir de uma maior abertura para o diálogo regular entre os diferentes atores do QJA, através de reuniões e encontros.

Mais adiante, estimularia também a criação de projetos específicos e integrados de revitalização desses patrimônios, maximizando assim, os benefícios dos eventos existentes no Quarteirão, proporcionando, dessa forma, a maior divulgação do conhecimento a respeito dos equipamentos pesquisados, pois “integrar é preciso". 


\section{REFERÊNCIAS}

ARAÚJO, L. M. Participação sociopolítica no planejamento turístico. Turismo: visão e ação, Balneário Camboriú, v. 8, n.1, p. 153-164, 2006.

ARGOLO, D.; BOMFIM, N. R. Pescadores, Cabaneiros e Feirantes: Novas percepções sobre a atividade turística na Baía de Camamu - Bahia - Brasil. Dissertação de Mestrado em Cultura e Turismo. Universidade Estadual de Santa Cruz. Abril, 2010.

BANDEIRA, P. Participação, articulação de atores sociais e descobrimento regional. Brasília: IPEA, 1999.

BAHIA, Secretaria da Cultura e Turismo. Roteiros Turísticos da Bahia - Costa do Cacau. Salvador, 2002.

BARDIN, L. Análise do conteúdo. Trad. Luís Antero Reto e Augusto Pinheiro. Lisboa: Edições 70, 2002.

BARRETTO, M. Turismo e legado cultural: as possibilidades do planejamento. Campinas: Papirus, 2000.

BENI, M. C. Política e planejamento de turismo no Brasil. São Paulo: Aleph, 2006.

BRANDON, K. Etapas básicas para incentivar a participação local em projetos de turismo voltado para a natureza. In: LINDBERG, K; HAWKINS, D. E. (Orgs.). Ecoturismo um guia para planejamento e gestão. Tradução de Leila C. de M. Darin; revisão técnica de Oliver Hillel. 5. ed. São Paulo: SENAC - São Paulo, 2005, p. 223252. Título original: A guide for planners and managers.

BRASIL. Lei 9.394, de 20 de dezembro de 1996. Lei de Diretrizes e Bases da Educação Nacional. Diário Oficial da União, Brasília, DF, 24 dez. 1996. Disponível em: <http://portal.mec.gov.br/seed/arquivos/pdf/tvescola/leis/lein9394.pdf>. Acesso em: 03/09/2009.

Turismo cultural: orientações básicas. Brasília: Ministério do Turismo, 2008.

Disponível em: <http://www.dominiopublico.gov.br/download/texto/tu000019.pdf>. Acesso em: 03/09/2009.

BONFIM, M. V. S. Quarteirão Jorge Amado e Comunidade Ilheense: relação de identidade. Revista Global Tourism, v. 4, n. 2, Nov. 2008. Disponível em: <http://www.periodicodeturismo.com.br/site/artigo/pdf/Jorge\%20Amado.pdf >. Acesso em: 27/09/2009.

BOUllón, R. C. Planejamento do espaço turístico. Tradução de Josely Vianna Baptista. Bauru, SP: EDUSC, 2002.

CARLOS, A. F. A. A (re)produção do espaço urbano. São Paulo: Edusp, 1994. 
CARnEIRO, E.; MIDLEJ, M. M. B. C.; PEREIRA, T. M. Caminhos do sertão" e Costa do Cacau: Cultura, Turismo e Desenvolvimento Regional em Zonas Turísticas do Estado da Bahia. Ilhéus: UESC, 6 ago. 2009. 38 p. CNPQ. Edital MCT/CNPq 02/2009 Ciências Humanas, Sociais e Sociais Aplicadas (Projeto de Pesquisa em andamento).

CARNEIRO, E. dos R. Os atrativos turísticos de Ilhéus - Bahia. 20 Fotografias (Acervo pessoal).

CHEVITARESE, L.; MATTOS, F. F. de. "Participação": Utopia ética pós-moderna para o turismo sustentável. In: TREVIZAN, S. (Org.). Comunidades Sustentáveis: a partir do turismo de base local. Ilhéus: Editus, 2006. p. 76-85.

DIAS, R. Planejamento do turismo: política e desenvolvimento do turismo no Brasil. São Paulo: Atlas, 2003.

GÂNDARA, J. M. G. La imagem de calidad ambiental urbana como recurso turístico: el caso Curitiba, Brasil. 471 f. Tese (Doutorado em Turismo em Desenvolvimento Sustentável) - Universidade de Las Palmas de Gran Canária. Las Palmas de Gran Canária, 2001.

Experiência turística. Conceito construído em sala de aula na disciplina: Qualidade da experiência na visitação de destinos turísticos. Ilhéus, Mestrado em Cultura e Turismo da Universidade Estadual Santa Cruz (UESC), jul. de 2009.

INSTITUTO BRASILEIRO DE GEOGRAFIA E ESTATÍSTICA (IBGE). Estatística de densidade populacional do Baixo Sul das Bahia. São Paulo: IBGE, 2000. Disponível em: <www.ibge.gov.br>. Acesso em: 20/10/2010.

IRVING, M. A. Participação - questão central na sustentabilidade de projetos de desenvolvimento. In: IRVING, M. A. (Org.) Turismo: o desafio da sustentabilidade. São Paulo: Futura, 2002.

KUMMER, L. Metodologia Participativa no meio rural: uma visão interdisciplinar. Conceitos, Ferramentas e Vivências. Salvador: GTZ, 2008.

LAKATOS, E. M.; MARCONI, M. A. Técnicas de pesquisa. Planejamento e execução de pesquisas, amostragens e técnicas de pesquisas, análise e interpretação de dados. 5 . ed. São Paulo: Atlas, 2002.

LEAL, F. P. O multiplicador turístico de Itacaré - BA: o caso dos meios de hospedagem. 2005. 46 f. Monografia (Graduação) - Universidade Estadual de Santa Cruz, Ilhéus, 2005.

LEME, F. M. P; JARDIM, G. T.; ROCHA, K. C.; DIAS, L. A.; SANTO, L. E. E.; BOMFIM, N. R. A percepção dos trabalhadores do Quarteirão Jorge Amado, IlhéusBahia, em relação ao patrimônio arquitetônico local. Patrimônio: Lazer \& Turismo. Santos, 3. ed., jul./ago./set. de 2008. Disponível em: 
<http://www.unisantos.br/pos/revistapatrimonio/images/artigos/Artigo3_JulAgoSet08.p df>. Acesso em: 12/09/2009.

MARCONI, M. A.; LAKATOS, E. M. Metodologia científica. 4. ed. São Paulo: Atlas, 2004.

MARTINS, C. Identidade: Percepção e Contexto. In: Martins, C. (Org.) Turismo, Cultura e Identidade. São Paulo: Rocca, 2003.

MENESES, J. N. C. História e Turismo Cultural. Belo Horizonte: Autêntica, 2004.

MENEZES, J. S. Quarteirão Jorge Amado. Um potencial local para o turismo cultural na cidade de Ilhéus. Ciudad Virtual de Antropología y Arqueología. Disponível em: <http://www.naya.org.ar/turismo/congresso2003/ponenciais/JulianaMenezes.htm>.

Acesso em: 15/09/2009.

MURTA, S. M.; ALBANO, C. (Orgs.). Interpretar o patrimônio: um exercício do olhar. Belo Horizonte: UFMG, 2002.

PERUZZO, C. M. K. Comunicação nos movimentos populares. Petrópolis: VOZES, 1998.

PETROCCHI, M. Turismo: planejamento e gestão. 2. ed. São Paulo: Pearson Prentice Hall, 2009.

ROMEIRO, A. R. Economia ou economia política da sustentabilidade. In: MAY, P. H.; LUSTOSA, V. V. (Orgs.). Economia no meio ambiente: teoria e prática. 5. ed. Rio de Janeiro: Elsevier, 2003, p. 1- 60.

SAVOIE-ZAJC L.; KARSENT, T. Introduction à la recherché em education. 2 ed. Quebec: Editions du CRP, 2000.

SIVIERO, A. Os elementos do espaço turístico urbano no processo de planejamento: uma análise da área central de Curitiba / PR. Dissertação (Mestrado) Universidade Federal do Paraná - Programa de Pós-Graduação em Geografia, 2005. Disponível em: <http://hdl.handle.net/1884/2354\&gt>. Acesso em: 02/08/2009.

VIEIRA JÚNIOR; A. ANDRADE, P. S. Da capitania de São Jorge de Ilhéus à Costa do Cacau: a memória como subsídio na construção de um produto turístico GLS. Disponível em:

<http://snh2007.anpuh.org/resources/content/anais/astor\%20vieira\%20junior.pdf>.

Acesso em: 10/12/2007.

VINHAES, J. C. São Jorge dos Ilhéus: da capitania ao fim do século XX. Ilhéus: Editus, 2001.

Recebido em: 13-10-2010.

Aprovado em: 13-11-2010. 